\title{
EFFECT OF CONTINUAL DECOMPRESSION USING HOLTER VALVE ON WEIGHTS OF CEREBRAL HEMISPHERES IN CHILDREN WITH HYDROCEPHALUS AND SPINA BIFIDA CYSTICA
}

\author{
BY \\ JOHN L. EMERY \\ From the Department of Pathology, The Children's Hospital, Sheffield
}

(RECEIVED FOR PUbliCATION JANUARY 26, 1964)

The introduction of an adequate method of producing a sustained drainage of cerebrospinal fluid from the cerebral ventricles into the heart using the Holter valve has introduced a new era in the treatment of children with congenital hydrocephalus. Many children who otherwise would have died within days of birth survive for months and years (Brit. med. J., 1960; Macnab, 1959, 1963). The question that arises is what effects, if any, this longstanding decompression has on the subsequent development of the brain?

Hydrocephalus in infants has many causes but the single most common group available is that of hydrocephalus associated with spina bifida cystica and the Arnold-Chiari deformity, and this study is confined to that group.

One of the difficulties in investigating these cases is that there is no adequate control material. Our own figures suggest that over $90^{\circ}$ of untreated cases die within a few weeks of birth and thus the few untreated cases that survive must come under the heading of "spontaneous arrest'. The only possible comparison that the pathologist is able to make is one between treated cases (which must include a few who would have arrested spontaneously) and the small proportion of the total population of hydrocephalics untreated that have either undergone complete or relative spontaneous arrest.

Measurement of the whole of the central nervous system is an impractical task. In children with meningomyeloceles and the Arnold-Chiari deformity with hydrocephalus there are deformities in all parts of the central nervous system including the aqueduct (MacFarlane and Maloney, 1957), but the most obvious are abnormalities in the region of the medulla and the meningomyelocele (Russell, 1949).

The present clinical treatment of these children's brains is chiefly directed at preventing the distension of the lateral cerebral ventricles. Thus, the cerebral hemispheres are the most likely structures to be directly affected both by the disease and by its treatment. In the present study, the criterion used was the weight of a single cerebral hemisphere, i.e. a portion of the brain in which the corpus callosum, the cerebral peduncle, and the floor of the third ventricle are divided. No standard weights of normal hemispheres are available and so the normal range had first to be determined.

The present paper is concerned with the weights of a single cerebral hemisphere from three groups of children coming to necropsy; (i) those who appear to have completely normal brains, (ii) those with untreated hydrocephalus, and (iii) those from children treated with the Holter valve and in whom the valve appeared to have been working satisfactorily for more than six weeks.

\section{Material and Methods}

The normal series of brains came from routine necropsies carried out by the Department of Pathology at the Children's Hospital, Sheffield. The brains were dissected by cutting the corpus callosum throughout its entire length and then the interthalamic ramus and the floor of the third ventricle. The hemispheres were then removed by cutting directly across the cerebral peduncles. The hemispheres were weighed both fresh and after fixation. The weights of the two hemispheres were averaged. Any brain coming from a child having any known neurological abnormality, mental deficiency, spasticity, or in whom convulsions had been known to occur, or in which the brain appeared in any way abnormal at the time of necropsy or on later examination, was excluded.

Hemispheres from 280 brains were used for final analysis. These were charted against postnatal age, and the mean and percentile lines were derived by conventional means. 
The routine procedure with brains from the children with hydrocephalus is to remove part of the cerebrospinal fluid from the cadaver on the day of death and to replace it by an equal volume of formal saline, a technique not unlike an exchange transfusion. This enables the brain to be fixed internally at the time of necropsy. At necropsy, the whole of the skull including the spinal column is removed as one specimen, the only portion of the brain being exposed at this time being the undersurface of the frontal lobes where they overlie the roof of the orbits. After fixation for a further few days, the skull is opened and the hemispheres removed and weighed as in the case of normal brains. In the presence of ventriculitis or haemorrhage, the pus and blood clot is removed from the ventricle before weighing, i.e. the ventricles are always weighed completely empty and clean.

Cases were only excluded from this series if ventriculitis was extreme and the inner surface of the brain was in any way indistinct. Brains were also excluded that contained

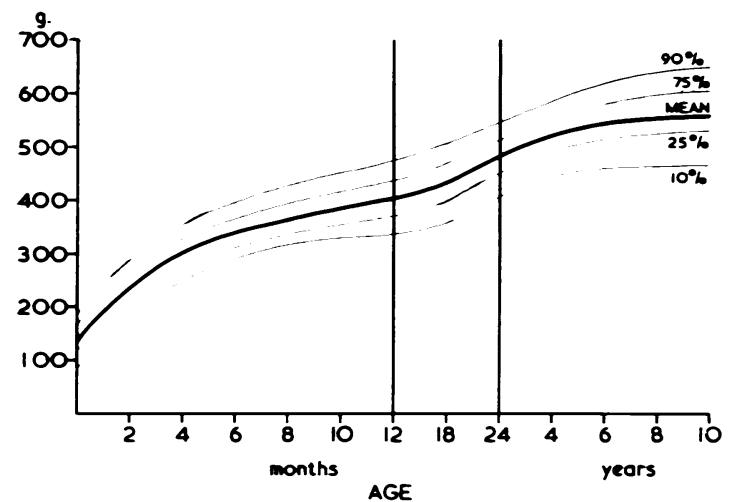

FIG. 1.-The mean and percentile lines of the weights of a single cerebral hemisphere from 280 normal brains.

areas of interstitial haemorrhage or large areas of encephalomalacia but not if they contained small ventricular dilatations associated with ventricular punctures (Grainger and Lorber. 1963; Lorber and Grainger, 1963; Laurence, 1958).

As a period of six weeks appears to be the minimal length of time necessary to show any significant growth of the brain and also children dying within six weeks of insertion of the Holter valve often had gross ventriculitis, all such brains were excluded. Thus, from a series of over 200 brains available from children with hydrocephalus related to the Arnold-Chiari deformity, there were 94 from children who had had no treatment of the brain. Of the children treated with the Holter valve, there were 5 clean brains from children dying between seven weeks and five months after insertion of the valve and 27 in whom the valve had been inserted and had been apparently functioning satisfactorily for six months or more.

In none of the latter group did I consider that the hydrocephalus was the principal immediate cause of death. It is not always obvious why some of the children with hydrocephalus and Arnold-Chiari deformity die, and this particularly applies to children below the age of 6

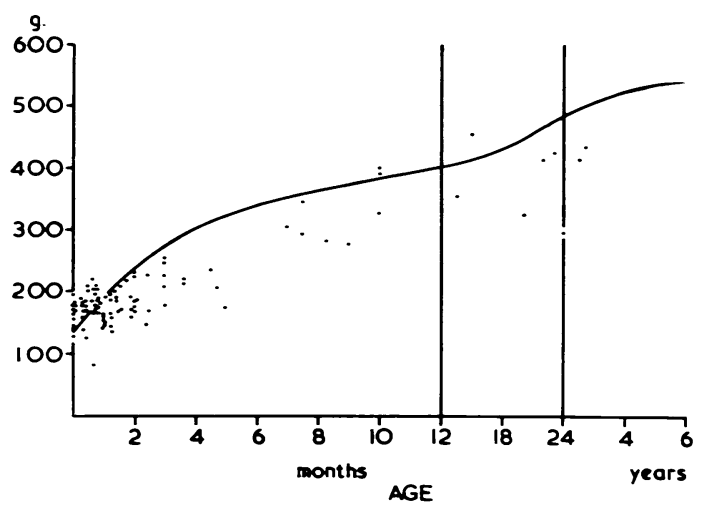

FIG. 2.-The weights of a single cerebral hemisphere from 94 children with the Arnold-Chiari deformity in whom no direct treatment for hydrocephalus had been carried out. The dark line represents the means of normal brains.

months. While many of the children dying soon after birth do so with gross ventriculitis, the majority that have been treated satisfactorily with the Holter valve and that have died over the age of 6 months have done so as the result of a disease completely outside the central nervous system, most being due to pulmonary and renal lesions.

All of the treated cases of hydrocephalus were under the surgical care of Mr. R. B. Zachary and the medical care of Dr. J. Lorber. The criteria for the start of treatment by insertion of the Holter valve and the production of a ventriculocaval shunt was the presence of an increasing hydrocephalus and an intracranial pressure of over 300 $\mathrm{mm}$. of water.

\section{Results and Discussion}

The mean weights of the normal cerebral hemispheres together with the $10,25,75$, and 90 percentiles are shown in Fig. 1.

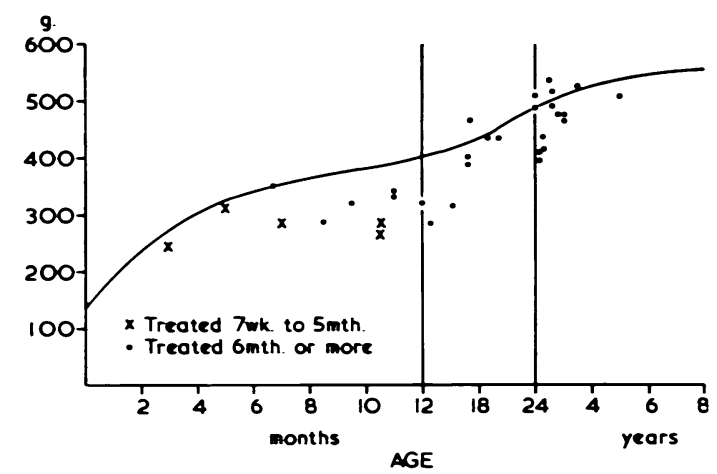

FIG. 3.-The weights of the hemispheres from 5 children in whom drainage using the Holter valve had been effective for between seven weeks and five months and 27 cases in whom the Holter valve had been functioning apparently normally for six months or more. The solid line represents the weights of normal hemispheres. 
TABLE

RATIO OF WEIGHTS OF CEREBRAL HEMISPHERES TO LIVER (HEMISPHERE LIVER) IN NORMAL CHILDREN, ARRESTED HYDROCEPHALICS, AND HYDROCEPHALICS TREATED BY LONG-TERM DECOMPRESSION

\begin{tabular}{|c|c|c|c|c|c|c|c|}
\hline \multirow{2}{*}{ Age at Death } & & \multicolumn{2}{|r|}{ Normals } & \multicolumn{2}{|c|}{ Untreated Hydrocephalics } & \multicolumn{2}{|c|}{ Treated Hydrocephalics } \\
\hline & & $\begin{array}{l}\text { No. of } \\
\text { Cases }\end{array}$ & Mean Ratio and Range & $\begin{array}{l}\text { No. of } \\
\text { Cases }\end{array}$ & Ratio and Range & $\begin{array}{l}\text { No. of } \\
\text { Cases }\end{array}$ & Ratio and Range \\
\hline $\begin{array}{l}0-10 \text { days } \\
2-6 \text { mth. } \\
18 \text { mth. }-5 \text { y. }\end{array}$ & $\begin{array}{l}\cdots \\
\cdots \\
\cdots\end{array}$ & $\begin{array}{l}12 \\
12 \\
12\end{array}$ & $\begin{array}{l}1 \cdot 20(0 \cdot 66-2 \cdot 54) \\
1 \cdot 32(1 \cdot 02-1 \cdot 8) \\
0.98(0 \cdot 79-1 \cdot 44)\end{array}$ & $\begin{array}{r}12 \\
12 \\
4\end{array}$ & $\begin{array}{l}1 \cdot 15(0 \cdot 77-1 \cdot 8) \\
0.94(0 \cdot 65-1 \cdot 83) \\
1 \cdot 04(0.8-1 \cdot 23)\end{array}$ & 12 & $1 \cdot 20(\overline{0 \cdot 74}-1 \cdot 8)$ \\
\hline
\end{tabular}

The weights of the hemispheres from 94 untreated hydrocephalics with the Arnold-Chiari deformity and meningomyelocele are shown in Fig. 2, and the corresponding hemisphere weights from five children decompressed for from between seven weeks and five months and from 27 children who had been treated for six months or more in Fig. 3. In both these illustrations the mean line of the normal series shown in Fig. 1 is also included.

When the untreated series is considered, there seems to be a difference between brains in children dying around the time of birth and those dying during the next few months. Of the children dying within 24 hours of birth, only one was below the normal mean line while 8 were considerably above it. If the normal range of 25 th to 75 th percentiles are excluded there are 7 hydrocephalic hemispheres over the 75 th percentile and none below the 25 th percentile. The same appears to hold good for the two weeks after birth when 26 of 32 hemispheres were over the 50 th percentile. Over this age we did not see a single hemisphere in the untreated group over the normal 50th percentile until the tenth month. Potter (1961) noted that the hydrocephalic brain can be heavier than normal at birth, but she does not give weights. Our figures support her observations and indicate that the weights of the hemispheres are usually greater than normal at the time of birth. In children with hydrocephalus who survive untreated for less than six months after birth, the significance of the weight of the brain is difficult to assess. Many of these infants show other quite definite evidence of a postnatal reduction in bone growth as shown by the costochondral junction, and the majority of children are grossly wasted. Most have had chronic infection either of the ventricles of the brain or renal tract, and virtually all have had infection of the meningomyelocele. It is not practical to assess the weights of organs in such children in relation to their crown rump length, the abnormal skull, and deformities of the spine, nor to their total body weights, because of the accumulation of fluid in the brains and often in the renal tract, and their obvious gross weight abnormality.
Of the organs that appear clinically and histologically to be least often subjected to abnormality in these unfortunate children, the liver is the most obvious.

When the ratio of the weight of the cerebral hemisphere to that of the liver was worked out for 12 hydrocephalics and for 12 normal children dying within 10 days of birth, no difference was obvious (Table).

There were 10 in the untreated group who died between 1 and 18 months (Fig. 2): 3 had hemisphere weights above the mean line but 5 were below the 10th percentile. These children fall into the category of apparent or partial 'spontaneous arrest'.

When the brains of the untreated children who died over the age of 18 months are considered, none of 6 brains was up to the normal 75th percentile and 3 were below the 10th percentile. The liver weight was available for only 4 of these children and the ratio of hemisphere to liver weights in these 4 all fell entirely within the range of the normal series (Table 1).

If we consider the hemispheres from the children whose hydrocephalus had been treated, a comparison of the scatter seen in Figs. 2 and 3 shows that in the children dying below the age of 18 months there is no difference between the treated and untreated group. In the children dying over the age of 18 months, we have many more cases, and here the treated hemispheres appear to be much nearer the normal mean than do the untreated.

All of the treated hemisphere weights fell within the 10th to 90th percentile for normals. Most of these children were in a state of good general nutrition. When the ratio of the brain to liver weights was estimated for this group, 12 matched normal brains showed a mean ratio of $0.98(0.79$ to 1.44$)$, the 4 untreated hydrocephalics had a ratio of $1.04(0.8$ to $1 \cdot 23)$, and the 12 treated hydrocephalics had a ratio of $1 \cdot 20(0.74$ to $1 \cdot 8)$. While these figures do not show any statistically significant difference, there is no doubt that the hemispheres of the treated hydrocephalics are at least as heavy as those of normal children of the same age.

Great care must be taken before attempting to 
draw any conclusions from the material presented here. In children with hydrocephalus with the Arnold-Chiari deformity, the central nervous system is only part of the picture and these children form a group of almost infinite variety, some children having relatively simple deformities of the nervous system and others having scarcely one normal organ in the whole body. Again, we cannot take the untreated series as a true comparison for the treated-the 'untreated' children that survive the newborn period are only a very small number, and these are mainly the children with minimal primary deformities who have outlived the newborn period. It is with this group that the studies of Laurence (1958) and Merrill, Isom, Anslow and Pinkerton (1962) are concerned, and our finding of a reasonably normal brain weight in such infants perhaps supports the optimism of their findings.

The treated group consists chiefly of children who, with no doubt at all, would have died in the newborn period if treatment had not been carried out, and since they were selected clinically as children with a progressive hydrocephalus and abnormally high intracranial pressure, it is most unlikely that this group contains any child in whom a 'spontaneous arrest' was likely to have occurred.

A further point is that of the validity of any comparison of these children with the growth pattern in normal children.

A curious feature that is apparent in both Figs. 2 and 3 is that the weights of the hemispheres give the impression of starting out around the normal mean at birth, falling below it during the first year, and then recovering to the normal mean after the second year. Are these induced spontaneous arrests (Taylor, Milliken and Davison, 1960)? The brains of children with the Arnold-Chiari deformity are quite abnormal apart from the presence of hydrocephalus, and the pattern of brain weight increase that we have recorded may represent the natural growth pattern of this type of dysplastic brain. On the other hand, the at least normal weights at birth and the apparent low weights following birth and the rapid fall off in the untreated series suggests that an increased intracranial pressure may somehow have prevented the growth of the brain. The solution to this problem will only be found when a sufficient number of children have been treated with decompression at a very early stage and before the brain has been subjected to enough increase in pressure in the newborn period to affect its blood supply, i.e. before it is grossly hydrocephalic.

The weights of the cerebral hemispheres are only one gross sign of growth and there is no necessary parallel intellectual development. Though of normal weight, the hemispheres from the treated hydrocephalics are still very abnormal (Emery, 1964). In hemispheres with gross ventricular dilatation, there is, of necessity, a great increase in the length of the connecting nerve fibres both intracortical and connecting the cortex with the brain-stem. Many of the latter fibres can be of normal length in the collapsed treated brain. Such factors are likely to influence the function of the brain but not its weight.

The present study presents more problems than it solves but there are some practical and tentative points that the results suggest. The weights of the hemispheres of the treated hydrocephalics appear to be more near the normal than those of the few 'spontaneously arrested' hydrocephalics that we have been able to examine. Does this suggest that a waitand-see policy regarding these cases is not justified on a long-term basis? Does the apparent suppression of brain growth in the untreated hydrocephalics during the first few weeks after birth suggest that it may be necessary to commence ventricular drainage within the neonatal period if a completely normal growth pattern is to be attempted?

\section{Summary}

In children with congenital hydrocephalus associated with the Arnold-Chiari deformity, the weight of the cerebral hemispheres appears to be normal at birth. In untreated cases dying before the age of 6 months, there is a suppression of hemisphere growth by weight. In the untreated cases that survive for more than 18 months the hemisphere weight again approaches the normal. In children treated by prolonged ventricular drainage the brain weight was in all instances between the normal 10th and 90th percentile for the age of the child.

It is a pleasure to be able to record the technical help of Miss V. Arrowsmith and the financial assistance of the Muscular Dystrophy Association and the Endowment Fund of the United Sheffield Hospitals.

\section{REFERENCES}

Brit. med. J. (1960). Annotation. Surgical treatment of hydrocephalus. 2, 1372.

Emery, J. L. (1964). The gross intracranial results of longstanding decompression of the brain in children with hydrocephalus and meningomyelocele. Develop. Med. Child. Neurol. In the press.

Grainger, R. G. and Lorber, J. (1963). Development of ventricular diverticula following ventricular puncture in hydrocephalic infants. VI Symposium Neuroradiologicum, Roma, 1961. Acta radiol. (Stockh.), 1, n.s., 569.

Laurence, K. M. (1958). The natural history of hydrocephalus. Lancet, 2, 1152.

Lorber, J. and Grainger, R. G. (1963). Cerebral cavities following ventricular punctures in infants. Clin. Radiol., 14, 98.

MacFarlane, A. and Maloney, A. F. J. (1957). The appearance of the aqueduct and its relationship to hydrocephalus in the ArnoldChiari malformation. Brain, 80, 479. 
Macnab, G. H. (1959). The Spitz-Holter valve. J. Neurol. Neurosurg. Psychiat., 22, n.s., 82.

- (1963). Treatment of hydrocephalus. In Modern Treatment Yearbook, p. 116. Medical Press, London.

Merrill, R. E., Isom, J. B., Anslow, R. M. and Pinkerton, J. A. (1962). Hydrocephalus and meningocele-The course of 100 patients. Pediatrics, 30, 809.
Potter, E. L. (1961). Pathology of the Fetus and Infant, 2nd ed., p. 430. Year Book Medical Publishers, Chicago.

Russell, D. S. (1949). Observations on the Pathology of Hydrocephalus. Spec. Rep. Ser. med. Res. Cown. (Lond.), No. 265.

Taylor, A. R., Milliken, J. R. and Davison, P. P. (1960). Long-term follow-up of hydrocephatic infants treated by operation. Brit. med. J., 2, 1356.

\section{ERRATA}

The Author regrets the following errors in his paper 'Hirschsprung's Disease', which appeared in this journal, volume 39, p. 109.

On p. 114; column 2, line 3; for dilated, read distal.

On p. 115, State, D. (1963). Segmental colon resection etc.; for Surg. Gynec. Obstet., read Amer. J. Surg.

On p. 115; Add Duhamel, B. and Duhamel, J. (1962).

Les formes anales de la maladie de Hirschsprung. Ent. Bichat., 257. 